\title{
Feasibility of Different Corrective Control Options for the Improvement of Transient Stability
}

DOI:

10.1109/PTC.2017.7981015

\section{Document Version}

Accepted author manuscript

Link to publication record in Manchester Research Explorer

\section{Citation for published version (APA):}

Morales Alvarado, J., Papadopoulos, P., \& Milanovic, J. V. (2017). Feasibility of Different Corrective Control Options for the Improvement of Transient Stability. In PowerTech, 2017 IEEE Manchester

https://doi.org/10.1109/PTC.2017.7981015

\section{Published in:}

PowerTech, 2017 IEEE Manchester

\section{Citing this paper}

Please note that where the full-text provided on Manchester Research Explorer is the Author Accepted Manuscript or Proof version this may differ from the final Published version. If citing, it is advised that you check and use the publisher's definitive version.

\section{General rights}

Copyright and moral rights for the publications made accessible in the Research Explorer are retained by the authors and/or other copyright owners and it is a condition of accessing publications that users recognise and abide by the legal requirements associated with these rights.

\section{Takedown policy}

If you believe that this document breaches copyright please refer to the University of Manchester's Takedown Procedures [http://man.ac.uk/04Y6Bo] or contact uml.scholarlycommunications@manchester.ac.uk providing relevant details, so we can investigate your claim.

\section{OPEN ACCESS}




\title{
Feasibility of Different Corrective Control Options for the Improvement of Transient Stability
}

\author{
Juan D. Morales, Student Member IEEE, Panagiotis N. Papadopoulos, Member IEEE, Jovica V. Milanović, Fellow, IEEE \\ School of Electrical and Electronic Engineering \\ The University of Manchester \\ Manchester, UK \\ juan.moralesalvarado@postgrad.manchester.ac.uk,panagiotis.papadopoulos@manchester.ac.uk, jovica.milanovic@manchester.ac.uk
}

\begin{abstract}
Corrective control actions for Transient Stability Improvement (TSI) could offer a solution to possible problems arising in modern stressed power networks operating under higher level of uncertainty. A comparative analysis of the most widely used corrective TSI methods is presented in this paper. The impact of the different Corrective Measures (CMs) on transient stability is investigated for different size of equipment, by calculating the additional time that the system is capable of withstanding severe disturbances at different locations. A comparison between different $\mathrm{CMs}$ is also performed, to identify the conditions under which each measure is most effective and therefore guide the design of stabilization strategies for large power systems. The work in this paper contributes specifically to the decentralized real-time stabilization of power systems.
\end{abstract}

Index Terms-Corrective control, decentralized real time stabilization, transient stability assessment, transient stability improvement.

\section{INTRODUCTION}

Market rules and the increasing use of uncertain renewable energy sources, most commonly connected through power electronics, are altering drastically the dynamic behavior of power systems. This tendency might drive power systems to operate in more stressed conditions and possibly closer to their stability limit. Under this scenario, corrective control for Transient Stability Improvement (TSI) becomes a valuable option to deal with the issues of current and future networks.

Several corrective control methods for TSI exist, such as connection of braking resistors [1-6], fast valving schemes in thermal generators [7-15], switched series capacitors [16], switched shunt capacitors [17], FACTS devices [18], control of HVDC links [19], islanding schemes [19], and generator and load shedding [19]. Previous work reported in the literature studied each method independently focusing mainly in the modelling and in the control of the insertion-removal of the specific devices to optimize the impact on TSI; some existing comparative studies [18] analyzed similar Corrective Measures (CMs) based on FACTS devices. Therefore, little work has been done to assess and compare the application and effectiveness of different CMs in a comprehensive way.

This work was partly supported by the collaborative EPSRC-India project ACCEPT (grant number: EP/K036173/1) and in part by the School of Electrical and Electronic Engineering, The University of Manchester.
This paper focuses on assessing the impact of different CMs for TSI. This is done by investigating the increase in the critical clearing time of a One-Machine Infinite Bus (OMIB) test network subjected to various severe disturbances with the insertion of selected CMs. A comprehensive assessment methodology is applied considering several scenarios that cover various aspects of power system operation. Both strong and weak power systems are studied as well as the effect of different degrees of support from the generator AVR controls. The followed approach includes the evaluation of different sizes or types for each CM to assess their effectiveness and to establish the range and operating conditions that each is most appropriate. Guidelines for the effective implementation of $\mathrm{CMs}$ in different situations are therefore provided.

\section{TRANSIENT StABILITY IMPROVEMENT METHODS}

CMs for TSI are activated only after a severe disturbance occurs. Therefore, all devices involved should not operate under normal operating conditions. Some CMs such as FACTS devices, in addition to TSI, can also offer small-signal stability improvement, reactive compensation, etc., and hence operate continuously. The main function of HVDC links is to transfer power, rather than improve stability. Generation tripping, load shedding and islanding schemes are usually more radical measures and should be used only as a last resort. In addition, these CMs could be also used for frequency and voltage support besides TSI. This paper will discuss only CMs exclusively dedicated to TSI; which are Braking Resistors (BR), Switched Shunt Capacitors (Shunt-C), Fast Valving (FV) and Switched Series Capacitors (Series-C).

The TSI effect of the selected measures can be explained using the simplified synchronous machine swing equation and the power-angle equation for an OMIB system defined by (1) and (2), respectively, and shown in Fig. 1.

$$
\begin{aligned}
& \mathrm{p} \omega=\frac{1}{2 H}\left(P_{m}-P_{e}\right) \\
& P_{e}=\frac{E_{q} V}{X_{E Q}} \sin \delta
\end{aligned}
$$

Where $\mathrm{p}$ is the derivative with respect to time, $\delta$ is the angle between $E q$ and $V$ (rotor angle), $H$ is the inertia constant 
in seconds (s), $\omega$ is the rotor electrical angular speed, $P_{m}$ is the mechanical power of the generator, $P_{e}$ is the electrical power output of the generator, $E_{q}$ is the internal voltage of the generator, $V$ is the infinite bus voltage, and $X_{E Q}$ is the total equivalent reactance between $E_{q}$ and $V$, all in $p . u$.

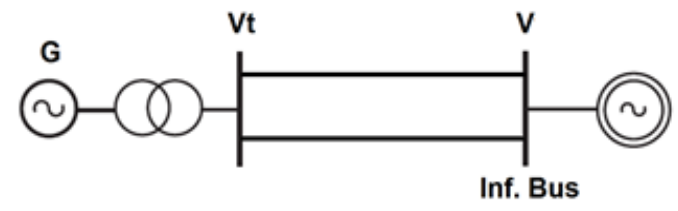

Figure 1. OMIB test system

Under normal conditions, $P_{m}$ is equal to $P_{e}$ in (1). The immediate effect after a severe disturbance in the system (e.g. three-phase fault at $V t$ ) will be an instant reduction of $P_{e}$ to zero hence accelerating the rotor of the generator due to the imbalance in (1). Any increase of $P_{e}$ or a decrease of $P_{m}$ just after the disturbance will reduce the acceleration of the rotor and the imbalance in (1) improving transient stability.

Fig. 2a shows the power-angle curve for the OMIB system of Fig. 1. Using the Equal Area Criterion (EAC), the critical stable condition without $\mathrm{CMs}$ is represented by the accelerating area 1-2-3-4 (A1) which is equal to the decelerating area 4-5-6 (A2). Fig. 2b and Fig. 2c show the rotor angle and speed deviation versus time, respectively, identifying all the important points of the power-angle curve.

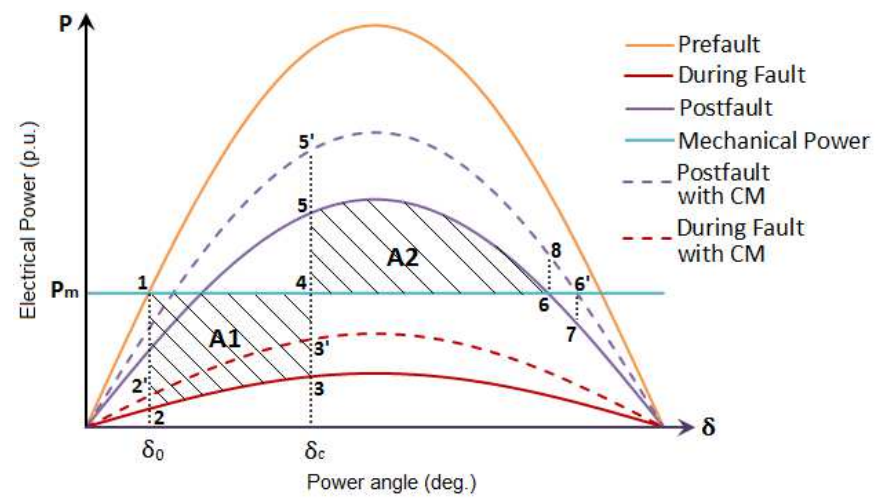

a)

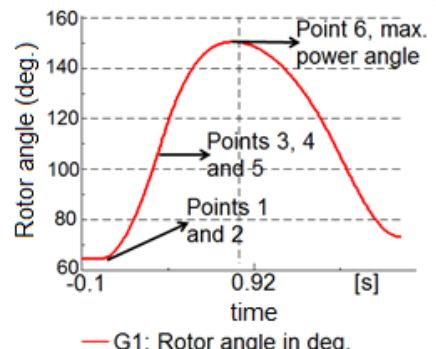

b)

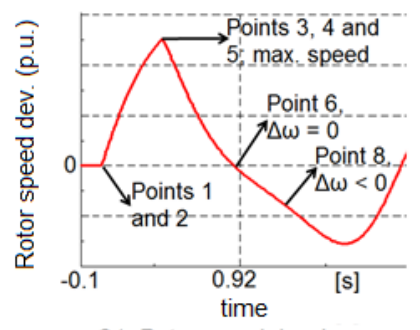

- G1: Rotor speed dev. in p.u.

c)
Figure 2. a) Power-angle curve; b) rotor angle; c) rotor speed deviation responses vs. time

A CM that increases $P_{e}$ will produce the new accelerating area 1-2'-3'-4 in Fig. 2a (the connection of the CM is assumed to occur at the exact moment the fault starts), which is less than A1. At the clearing angle $\delta c$ the rotor speed reaches its maximum value. After fault clearance, the increase in $P_{e}$ is maintained, hence the decelerating area is given by $4-5$ ' -6 '; which is greater than $\mathrm{A} 2$. If the $\mathrm{CM}$ reduces $P_{m}$ instead (i.e. FV), the effect is that the horizontal line 1-4-6 in Fig. 2a shifts downwards and the effect in the accelerating and decelerating areas is similar.

Up to this point, first swing stability has been improved and the back swing of the rotor begins, for which the greater decelerating area 4-5' 6' becomes a problem because the rotor will decelerate with more energy, and hence the generator might exhibit more oscillatory behavior than a case without CMs. Thus, the connection of the CMs should be temporary and ideally they should be switched off at or very close to point 6', where the speed deviation is equal to zero, to limit their effect on strictly improving the first swing stability. In the case of a critical stable scenario after the application of CMs (area 1-2'-3'-4 equal to 4-5'-6' in Fig. 2a), their disconnection exactly at point 6' adds the accelerating area 66'-7 to a marginally stable case, which might lead to instability. Therefore, the disconnection should be delayed for some time until the angle starts to decrease to point 8 , where the speed deviation has a negative value as shown in Fig $2 \mathrm{c}$. At this point the disconnection of the $\mathrm{CM}$ would reduce $P_{e}$ from point 8 to 6 , and no accelerating area would be added. The impact of this delayed disconnection should have minimum effect on further oscillations as the decelerating area 6-6'-8 is small.

In this paper, the different CMs (i.e. BR and Shunt-C) are assumed to be connected when the fault is applied or shortly after that (e.g. $20 \mathrm{~ms}$ ). The above mentioned CMs are disconnected after the speed deviation $(\Delta \omega)$ crosses zero and becomes negative (point 6 , shown in Fig. 2c), considering also a short delay time (i.e. $100 \mathrm{~ms}$ in this paper, point 8 shown in Fig. 2c). The short delay is added since it is important for the marginal case explained in the previous paragraph (area 1-2'3'-4 equal to 4-5' -6' in Fig. 2a) and it is not expected to affect significantly the rest of the cases (that are not marginally stable), as explained previously. Therefore, the delayed disconnection is applied to all cases in this paper, which also leads to a less complicated disconnection procedure, irrelevant to specific operating conditions. For the case of FV, its performance depends on the turbine characteristics (further discussed in Section II-D) and it is not connected or disconnected as the rest of the CMs mentioned above. More detailed information for each specific $\mathrm{CM}$ is provided in Section III.

\section{A. Braking resistor}

The connection of BR at the bus $V t$ in Fig. 1 after a disturbance will add an artificial load increasing the total electrical power $P_{e}$ in (2); thus improving transient stability.

As BR can control $P_{e}$ directly it is considered as one of the most effective CMs for TSI. Nevertheless, in the available literature the discussion with respect to the effect of the size of the device (in MW) is very limited. Larger BRs would absorb a larger amount of electrical power but would also cause larger voltage drops, decreasing $P_{e}$ in (2). Therefore, a balance between these two effects should be maintained. This criterion 


\section{ACCEPTED VERSION OF THE PAPER}

is indirectly applied in [3, 4, 6]. In addition, the difficulty to coordinate BR with other corrective actions could impose size limitations [6].

The size of BRs for TSI of individual power plants in [1, 2, $4,5]$ is defined to be able to stabilize a critical fault that initially causes instability, considering that the device is located close to the plant. This results in sizes between 500$1000 \mathrm{MW}$ for plants of capacities up to $2725 \mathrm{MW}$. For TSI of large areas with several power plants, a strategically located $1400 \mathrm{MW}$ BR size is reported in [3], following a similar criterion of critical-fault withstanding. Therefore, a practical upper limit for BR would be around $1500 \mathrm{MW}$ for TSI of individual power plants with capacities greater than $2000 \mathrm{MW}$ or large areas with more power plants. For TSI of individual power plants with capacities less than $1000 \mathrm{MW}$, BRs of up to 1 p.u. (generator base) should be adequate [4]. In this paper, an investigation for different BR sizes is carried out for an individual power plant using a range of values that go from a fraction of the capacity of the plant as suggested in the literature (and described above) to up to 2.5 times its capacity, to assess the actual impact on TSI.

\section{B. Switched Shunt Capacitor}

Connection of a Shunt-C at the bus $V t$ after a disturbance will increase $P_{e}$ by boosting the voltage in (2) and therefore improve stability. According to [16], the reactive capacity of a Shunt-C should be between 3 to 6 times that of a Series-C to achieve a similar effect on TSI, depending on the compensation level of the Series- $C$ with respect to the line it is connected to.

Since a Shunt-C for TSI is connected during fault conditions when the voltage is low, no overvoltages are expected to arise following its connection. Therefore, very high capacities could be used. In [16], the disconnection of a shunt reactor of $500 \mathrm{MVar}$ (similar effect to a connection of a Shunt-C) is reported as an effective way for TSI; hence a practical limit of 500 MVar for Shunt-C size could be adopted. Several sizes will be tested following the exact same procedure as in the case of BRs.

\section{Switched Series Capacitor}

The connection of Series-C between the transformer and the bus $V t$ in Fig. 1 after a disturbance will increase $P_{e}$ by reducing $X_{E Q}$ in (2). Series-C is usually sized depending on the reactance of the line it compensates (in percentage) and its power capacity. High levels of series compensation could cause subsynchronous resonance issues in systems with high degree of shunt compensation and very long transmission lines [19]. Therefore the application of Series-C for stabilization must be carefully studied, since it may cause further problems. The present paper tests several degrees of Series-C and will not consider possible subsynchronous resonance events.

\section{Fast valving}

In FV, valves start to close around $0.1 \mathrm{~s}$ after the fault, decreasing the generator mechanical power. If $P_{m}$ does not start to recover again quickly enough, the increase in the decelerating area after the first swing might cause oscillatory behavior of the rotor as discussed previously and could produce second swing instability [9]. Therefore, FV needs to be implemented with caution since it might exhibit negative impact on transient stability for some scenarios or turbine characteristics.

Fig. 3 shows typical FV characteristics of $P_{m}$ output as well as valve position versus time for fossil-fired and nuclear plants. The curves in Fig. 3 are typical curves obtained based on information taken from [7-9, 11-14] which present different curves for various FV schemes, according to manufacturer information, design characteristics and field tests. All the characteristics presented in the cited references are similar and the curves in Fig. 3 are considered a reasonable approximation for a typical mechanical power output characteristic in a FV scheme for each type of power plant. The FV response is usually fixed and not controllable for each case. Control Valves (CV) and Intercept Valves (IV) are capable of closing together, but since IV control over $70 \%$ of the total unit power, they are the most commonly controlled $[8,10,11,14,15]$. The use of CV and IV would bring greater stability benefits. However, it is not recommended because the sudden drop in pressure that occurs when both valves are closing could affect the boiler and control systems negatively [8]. It is also observed that even though the valves could take around up to $6 \mathrm{~s}$ to completely open again, $P_{m}$ reacts faster and goes back to the initial value in less time, approximately $2-3 \mathrm{~s}$, as shown in [7, 11-14] where the $P_{m}$ output versus time curve characteristics are presented, for different turbines in a FV scheme.

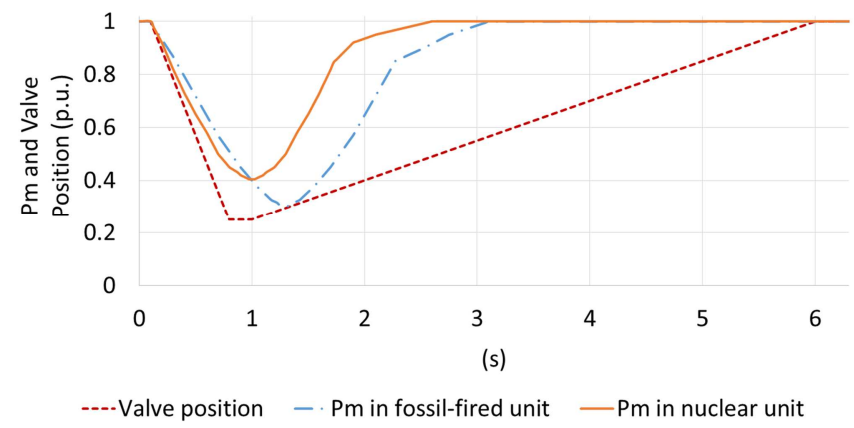

Figure 3. Typical mechanical power output and valve position vs. time for FV schemes

Initial research on FV considered feasible its application in fossil-fired and nuclear units. For fossil-fired units, actual test data is found in [8, 11-14]. Even in the cases when both IV and $\mathrm{CV}$ are used, the output power is reduced only to around $30 \%$ of the initial value in a total time that is usually about 1 to $1.3 \mathrm{~s}$. The power output goes back to the initial value 2 to $2.5 \mathrm{~s}$ afterwards. Theoretical approaches are discussed in [7-9, 11] for application of FV to nuclear units. It was established that the response of nuclear units would be faster (time to reach minimum power of $0.9 \mathrm{~s}$ and recovery time of $1.5 \mathrm{~s}$ approx.) but the mechanical power could be reduced only to about $40-60 \%$ of the initial output, i.e. higher compared to fossil-fired units. Although no actual implementation of FV for nuclear units is reported, its effect on TSI is investigated in the present paper for assessment purposes. The application of the FV in the present paper uses directly the characteristics shown in Fig. 3 as they represent reasonably the average performance of FV schemes for different types of power plants. 


\section{ACCEPTED VERSION OF THE PAPER}

\section{AsseSSMENT Methodology}

The system of Fig. 1 is used to assess the impact of the different CMs. Power Factory/Digsilent software is used for the simulations. All parameters have been defined based on typical values found in actual networks. The transmission system voltage is $220 \mathrm{kV}$ and the rated power of the $16 \mathrm{kV}$ generator G1 is 200 MVA. The assessment is done according to the following steps:

1) Step 1: Transient stability is assessed by calculating the Critical Clearing Time (CCT) for three-phase faults at a distance of $1 \%, 25 \%, 50 \%, 75 \%$ and $99 \%$ of the total length from bus $V t$ for one of the lines. The fault is cleared by disconnecting the faulted line. The CCT is the maximum allowable time at which a fault must be cleared before the system loses synchronism. The initial CCTs are calculated under three conditions: G1 without AVR, G1 with a DC excitation system IEEE type DC1A with a gain of 40 (referred to as AVR-1), and G1 similar to AVR-1 but with a high gain of 200 and a faster response comparable to a static exciter (referred to as AVR-2). The AVR scenarios are applied to two different cases: $\mathrm{G} 1$ with $\mathrm{H}=5.84 \mathrm{~s}$ (referred to as the strong system case) and G1 with $\mathrm{H}=2 \mathrm{~s}$ (referred to as the weak system case), both in a 200 MVA base. The objective is to assess the impact of the CMs for typical generators in power systems.

2) Step 2: CMs are activated after the fault happens for all scenarios of Step 1. In the case of BR and Shunt-C, they are connected $20 \mathrm{~ms}$ after the fault and disconnected $100 \mathrm{~ms}$ after the first zero crossing of the speed deviation as explained in Section II. The Series-C is connected immediately after the line tripping to avoid the flow of high fault short circuit currents through the device, and disconnected $5 \mathrm{~s}$ later. In this case, the Series-C is not disconnected as the BR and Shunt-C discussed in Section II because it helps voltage regulation after its connection, providing additional TSI. For FV, the characteristics shown in Fig. 3 for both nuclear and fossilfired units are directly applied to G1 as discussed; detailed governor controls are not considered.

3) Step 3: Except for FV, different sizes of the CMs are compared for better assessment of their positive impact. For BR and Shunt-C, sizes from 0.5 up to 2.5 p.u. referred to the generator base. For the Series- $\mathrm{C}$, compensation levels from $50 \%$ up to $95 \%$. The impedance of the Series-C refers to the reactance of one of the two transmission lines of the system in Fig. 1 (100 ohm each one).

4) Step 4: The effectiveness of the CMs will be assessed by how much additional CCT they provide, compared to the CCTs in Step 1. Hence CCT is the stability index to use in the present paper since it provides a direct measure of TSI.

\section{RESULTS AND DISCUSSION}

\section{A. CCT of Step 1 (without any CMs)}

The initial CCTs for Step 1 are shown in Fig. 4. For the strong system case, the CCT increases approximately linearly for faults up to $50 \%$ of the line length; for faults at further locations it follows an exponential characteristic which is most pronounced in the cases with AVRs. For the weak system, the CCT increases almost linearly for faults throughout the line.

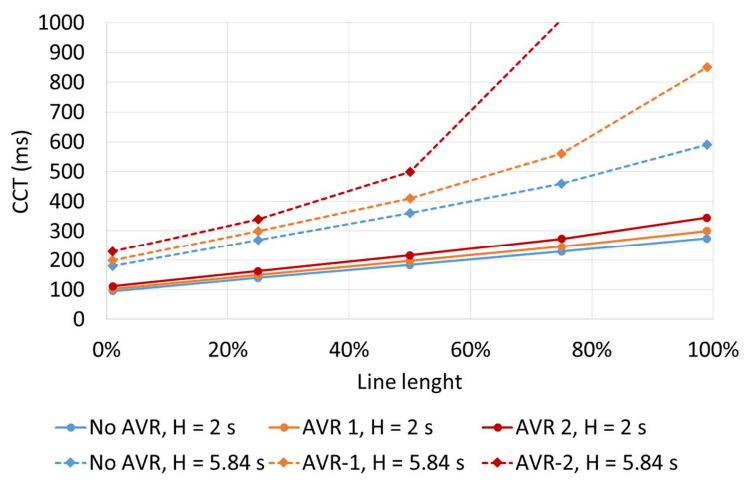

Figure 4. Initial CCT for the test network without CMs

\section{B. Effect of Shunt-C}

Fig. 5 shows results for the case when Shunt-C is used, for the weak system and for different sizes. For faults up to $25 \%$ of the line, the additional CCT increases linearly with the size of the Shunt-C. For faults at $50 \%$ of the line length and above, the characteristic is approximately exponential. For the strong system results show the same tendency, indicating that for all cases, the CCT always increases for faults far from G1 and for higher Shunt-C sizes.

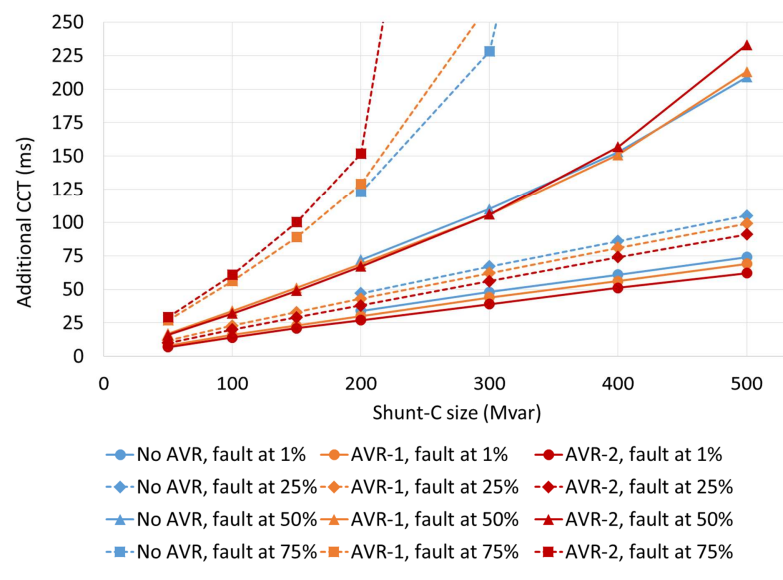

Figure 5. Additional CCT for Shunt-C, weak system

\section{Effect of $B R$}

Fig. 6 shows the improvement in CCT for the BR case in the weak system. For faults up to $25 \%$ of the line, the additional CCT increases approximately linearly with the size of BR up to 1 p.u. only. For sizes above 1 p.u. in these cases, the voltage drop due to the BR connection offsets the benefit in additional electrical power consumed decreasing the additional CCT improvements. The same tendency is observed for the strong system but only for faults at $1 \%$ of the line length. For faults at $50 \%$ of the line length and above, the characteristic is approximately linear to exponential in the weak system. A similar behavior is observed for the strong system for faults at $25 \%$ of the line length and above. Thus, a limitation considering the effect of large size BRs exists for critical faults close to G1 in all cases. However, TSI from BRs 


\section{ACCEPTED VERSION OF THE PAPER}

increases with the size for less critical faults far from G1 and better voltage support, especially in strong systems.

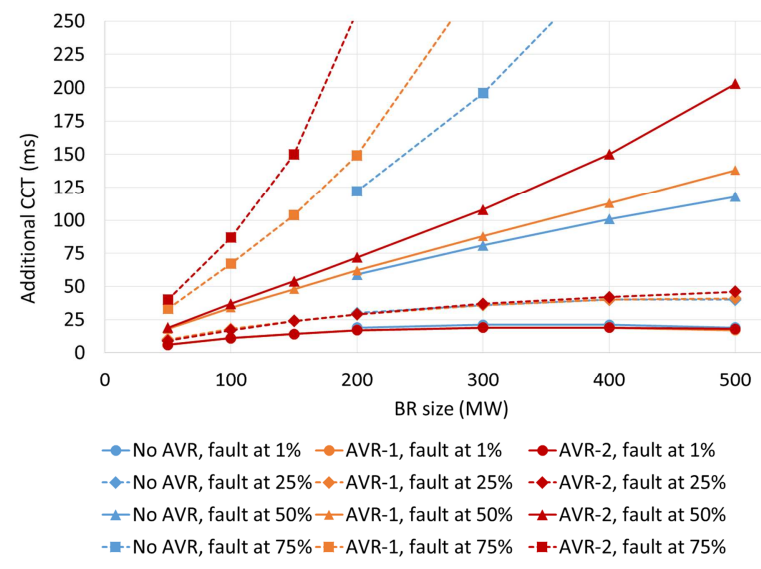

Figure 6. Additional CCT for BR, weak system

Comparison of Fig. 5 and Fig. 6 shows that the Shunt-C provides better improvement in additional CCTs than BR for faults up to $50 \%$ of the line length in the weak system. A similar tendency is also observed for the strong system. Therefore, for more critical faults close to G1, the Shunt-C is a better option, especially for weak systems.

It is important to notice that for faults above $50 \%$ of the line length, the exponential improvements observed in the additional CCTs might be caused due to the fact that the fault is closer to the infinite bus. Fig. 5 and Fig. 6 show that the additional CCTs for faults at $75 \%$ are considerable higher than results for faults up to $50 \%$, especially for devices of larger sizes (more than 1 p.u.). However, the present work aims at comparing different CMs and their effectiveness on TSI and therefore, the results presented in Figs. 5-6, especially for faults above $50 \%$ are meant to be mainly used in such a comparative manner.

\section{Effect of Series-C}

Fig. 7 shows results for the Series-C case in the weak system with no AVR and AVR-2 (fast acting AVR). The rest of the cases, not presented in the figure, show the same tendency. For any case and fault location, the additional CCT increases linearly with the compensation level and there is no exponential improvement as the other CMs analyzed in the present paper. The Series-C provides smaller improvement in the CCT compared to Shunt-C and BR for faults relatively far from G1. However, it provides larger improvement in CCT for faults close to G1 (up to $25 \%$ of the line). These faults are usually the most critical and difficult to stabilize and in general high CCTs are not achievable for such faults. Series-C could provide up to $70-80 \mathrm{~ms}$ of improvement in the CCT. In some of the studied cases, a large Shunt-C (above 1 p.u.) could also have a similar impact for faults close to G1. However, such high size of Shunt-C would not be practical to implement in some cases. The compensation level of Series-C for these conclusions to be true is $65 \%$ or above.

\section{E. Effect of $F V$}

For the FV case in the weak system, additional CCTs are smaller compared to other CMs. For faults up to $50 \%$ of the line length, the additional CCTs are less than $40 \mathrm{~ms}$. The improvement for faults at 1\%, shown in Fig. 8, is very small. For the strong system and AVRs (shown in Fig. 9), the observed improvement can be as good as the Shunt-C and BR for faults up to $25 \%$ of the line.

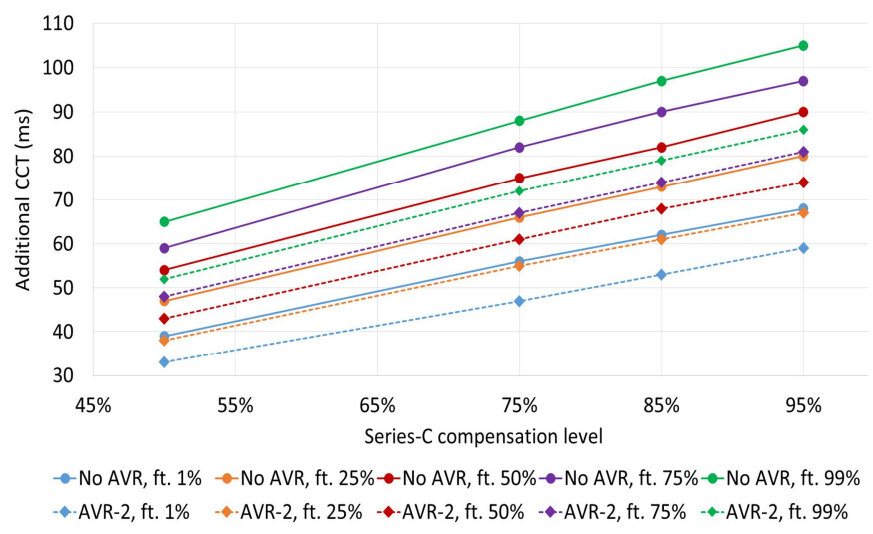

Figure 7. Additional CCT results for Series-C, weak system

For faults farther from G1, the results are considerably enhanced. These results show again an exponential characteristic for faults beyond 50\%, especially in the strong system. It is also observed that with the theoretical nuclear FV application, results are always better. This is expected, since its response is faster than the fossil-fired case as discussed in Section II and fast responses are more influential on TSI. Therefore, FV is not a good option for weak systems and/or critical faults with low voltage support. However, the results show better improvement in the rest of the cases.

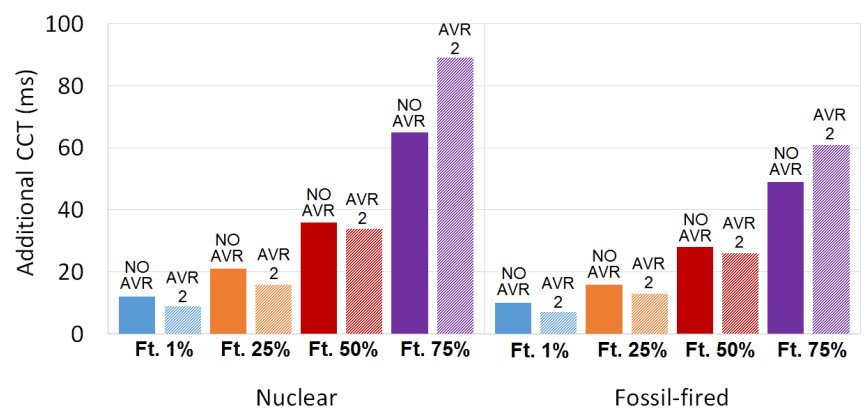

No AVR, ft. $1 \%$ AVR-2, ft. $1 \%$ No AVR, ft. $25 \%$ AVR-2, ft. $25 \%$ - No AVR, ft. 50\% $=$ AVR-2, ft. 50\% No AVR, ft. 75\% $=$ AVR-2, ft. $75 \%$

Figure 8. Additional CCT results for FV, weak system

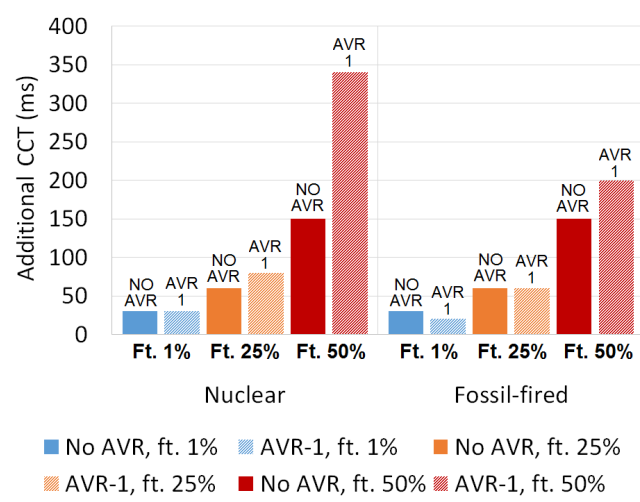

Figure 9. Additional CCT results for FV, strong system 


\section{ACCEPTED VERSION OF THE PAPER}

\section{F. Rotor angle vs. time response of different CMs}

Fig. 10 shows the rotor angle responses versus time before and after the application of CMs for equal Clearing Times (CT) for the case of a fault at $25 \%$ of the line with AVR-2 in the weak system. It is observed that the excursion of the angle after the application of the CMs is less for the Series-C, followed by the Shunt-C, BR and FV. Fig. 11 shows the rotor angle responses for the same case as Fig. 10 but with the new CCTs obtained after applying the CMs. It is observed here that the maximum excursion angle for all the cases is very close and the only way to assess the effectiveness of the CMs is by the additional CCTs obtained. It is noteworthy to verify that the initial ranking of the most effective CMs obtained by the initial rotor angle excursions in Fig 10 is verified by the resulting CCTs obtained in Fig. 11, confirming that the Series$\mathrm{C}$ is the best option for the case presented.

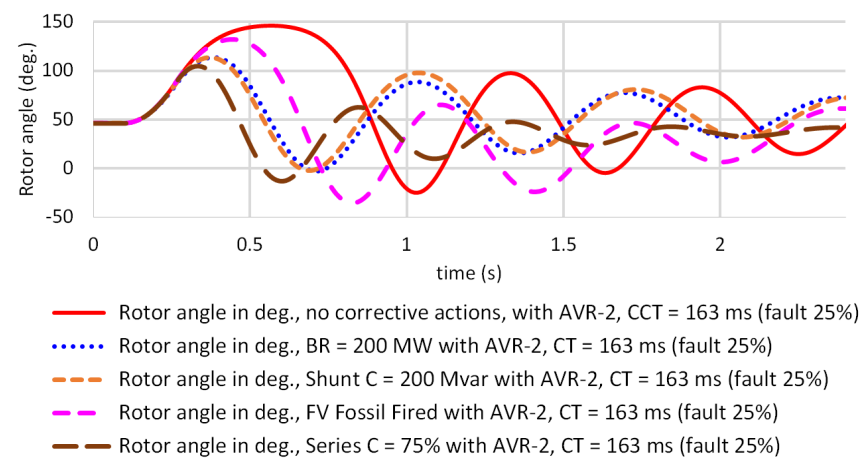

Figure 10. Rotor angle responses with and without CMs for the same CTs

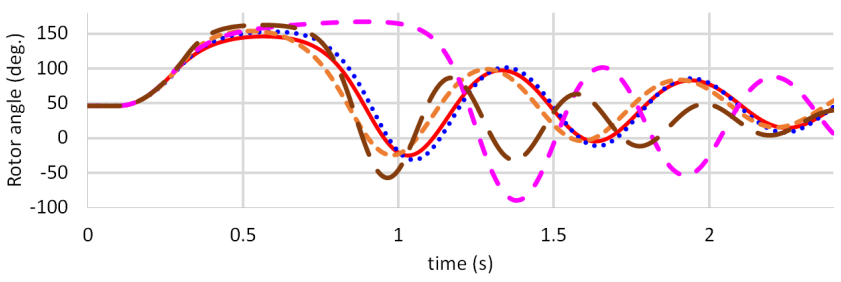

Rotor angle in deg., no corrective actions, with AVR-2, CCT = 163 ms (fault 25\%) ..... Rotor angle in deg., BR $=200 \mathrm{MW}$ with AVR-2, CCT = $192 \mathrm{~ms}$ (fault 25\%) - - Rotor angle in deg., Shunt C = 200 Mvar with AVR-2, CCT = $201 \mathrm{~ms}$ (fault 25\%)

- Rotor angle in deg., FV Fossil Fired with AVR-2, CCT = 176 ms (fault 25\%) - Rotor angle in deg., Series C $=75 \%$ with AVR-2, CCT $=218 \mathrm{~ms}$ (fault 25\%)

Figure 11. Rotor angle responses with and without CMs for their CCTs

\section{CONCLUSIONS}

The impact of four different CMs for TSI was investigated in this paper. The test system consisted of an OMIB network subjected to faults at different locations from most to less critical (close-in to far-end, three-phase faults from the generator). The obtained improvement in CCT is used for the assessment. Different scenarios were investigated to represent realistic operating conditions of power systems. Two cases with different generator inertias, representing strong and weak systems, combined with three additional voltage regulation scenarios, ranging from without AVR up to fast AVR response. Finally, the impact of different sizes and types of the selected CMs is discussed and compared.

From the variety of investigated cases, it is concluded that in general, Shunt-C devices are a better option for TSI than more conventional BR devices in most cases. Series-C devices represent the best option for the most critical faults although their potential benefit for less critical faults is limited. Finally, FV has less impact on TSI compared to other methods for critical faults close to generators, especially in weak systems. The findings in the present paper represent an important step towards the search for optimal deployment of CMs for the stabilization of large power systems.

\section{REFERENCES}

[1] W. H. Croft and R. H. Hartley, "Improving transient stability by use of dynamic braking," Transactions of the AIEE. Part III: Power Apparatus and Systems, vol. 81, pp. 17-24, 1962.

[2] H. M. Ellis, J. E. Hardy, A. L. Blythe and J. W. Skooglund, "Dynamic stability of the Peace River transmission system," IEEE Transactions on Power Apparatus and Systems, vol. PAS-85, pp. 586-600, 1966.

[3] M. L. Shelton, W. A. Mittelstadt, P. F. Winkelman and W. J. Bellerby, "Boneville Power Administration 1400-MW braking resistor," IEEE Trans. Power Apparat. Syst., vol. 94, pp. 602-611, 1975.

[4] S. S. Joshi, D. G. Tamaskar, "Augmentation of transient stability limit of a power system by automatic multiple application of dynamic braking," IEEE Trans. Power Apparat. Syst., vol. PAS-104, pp. 30043012, 1985.

[5] D. F. Peelo, D. W. Hein and F. Peretti, "Application of a $138 \mathrm{kV} 200$ MW braking resistor," Power Eng. Journal, vol. 8, pp. 188-192, 1994.

[6] A. A. Grobovoy and N. N. Lizalek, "Multiple dynamic brake and power system emergency control," International Conference on Power System Technology. Proceedings, vol. 2, pp. 1351-1355, 1998.

[7] W. A. Morgan, H. B. Peck, D. R. Holland, F. A. Cullen and J. B. Ruzek, "Modern stability aids for Calvert Cliff units," IEEE Trans. Power Apparat. Syst., vol. PAS-90, pp. 1-10, 1971.

[8] E. W. Cushing, G. E. Drechsler, W. P. Killgoar, H. G. Marshall, H. R. Stewart, "Fast Valving as an Aid to Power System Transient Stability and Prompt Resynchronization and Rapid Reload after Full Load Rejection," IEEE Trans. Power Apparat. Syst., vol. PAS-91, pp. 16241636, 1972.

[9] P. Kundur, and J. P. Bayne, "A study of early valve actuation using detailed prime-mover and power system simulation," IEEE Trans. Power Apparat. Syst., vol. 94, pp. 1275-1287, 1975.

[10] U. O. Aliyu and A. U. Chuku, "Investigation of transient stabilizing control effects on turbine - generator shaft torques," IEEE Transactions on Power Apparatus and Systems, vol. PAS-101, pp. 2619-2629, 1982.

[11] L. Edwards, J. D. Gregory, D. L. Osborn, J. H. Doudna, B. M. Pasternack, W. G. Thompson, "Turbine Fast Valving to Aid System Stability: Benefits and Other Considerations," IEEE Trans. Power Syst., vol. 1, pp. 143-153, 1986.

[12] J. H. Doudna, "Application and implementation of fast valving and generator tripping schemes at Gerald Gentleman Station," IEEE Transactions on Power Systems, vol. 3, pp. 1155-1166, 1988.

[13] B. M. Pasternack and N. B. Bhatt, "The Rockport Plant - Analysis of Temporary Fast Turbine Valving Tests," IEEE Trans. Power Syst., vol. 3, pp. 529-540, 1988.

[14] N. B. Bhatt, "Field experience with momentary fast turbine valving and other special stability controls employed at AEP's Rockport Plant," IEEE Transactions on Power Systems, vol. 11, pp. 155-161, 1996.

[15] R. Patel, T. S. Bhatti and D. P. Kothari, "Improvement of Power System Transient Stability Using Fast Valving: A Review," Electric Power Components and Systems, vol. 29 (10), pp. 927-938, 2001.

[16] E. W. Kimbark, "Improvement of System Stability by Switched Series Capacitors," IEEE Trans. Power Apparat. Syst., vol. PAS-85, pp. 180$188,1966$.

[17] D. Sutanto, W. R. Lachs, "Improving transient stability by containing accelerating energy," International Conference on Advances in Power System Control, Operation and Management, vol. 2, pp. 395-399, 2000.

[18] M. A. H. Sadi and M. H. Ali, "A Comprehensive Analysis of Transient Stability Enhancement Methods of Electric Power System," North American Power Symposium (NAPS), pp. 1- 6, 2015.

[19] P. Kundur, Power System Stability and Control. New York: McGrawHill, 1994. 